\title{
ISLAMIC ASTRONOMY IN CHINA: TWO NEW SOURCES FOR THE Huihui li ("ISLAMIC CALENDAR")
}

\author{
BENNO VAN DALEN AND MICHIO YANO \\ International Institute for Linguistic Sciences, Kyoto Sangyo University, Kamigamo, \\ Kita-ku, 603 Kyoto, Japan*
}

In this talk we will discuss some aspects of the exchange of astronomical knowledge that took place between the Muslim world and China in the thirteenth and fourteenth century. In that period both the eastern part of the Muslim world, consisting of Persia and surrounding countries, and China, ruled by the Yuan Dynasty, were part of the Mongol world empire. In particular in the period between 1260 and 1280, astronomers as well as astronomical books and instruments were exchanged between Persia and China. As a result, extensive descriptions of a Chinese luni-solar calendar can be found in Arabic and Persian astronomical works from the Mongol period, whereas a Chinese text entitled Huihui li ("Islamic Calendar") can be seen to be a translation of a typical Islamic astronomical handbook with tables and explanatory text, in Arabic and Persian called $z \bar{\imath} j$. Islamic astronomy had a good name in China because of its accurate prediction of eclipses, and the Huihui li was used parallel with the official Chinese calendar for almost 300 years.

The three slightly different versions of the Huihui li that are recorded in Chinese and Korean annals were studied by Japanese and Chinese scholars such as Kiyosi Yabuuti, Chen Jiujin, and Chen Meidong. However, until recently the Huihui li had never been systematically compared with Arabic and Persian astronomical handbooks written in the Muslim world. During the last two years we have started such a comparison in a research project at Kyoto Sangyo University. It turned out that most of the astronomical parameters underlying the tables in the Huihui li are not found in any of the around twenty Arabic and Persian handbooks that we consulted. We therefore tentatively assume that they are the result of an extensive observational program probably carried out at the Islamic Observatory in the Yuan capital Beijing. Also various innovations in the organization of the tables appear to be unique to the Huihui li.

In the course of our research, two important new sources for the study of the Huihui li were identified. Firstly, a Chinese manuscript of the Huihui li was discovered in the library of the Tōhoku University in Sendai in northern Japan. Secondly, an Arabic manuscript written in Tibet in 1366 turned out to have a large number of tables in common with the Huihui $l i$, in particular those for planetary motion.

We will now briefly discuss the three versions of the Huihui li that were known before and will summarize the historical information concerning the origin of the work which can be derived from them. Then we will continue by introducing the two new sources mentioned above and sketching some of the results that our preliminary investigation of them has yielded.

\section{The three versions of the Huihui li known before}

Until recently, research on the Huihui li was based on the following three Chinese sources:

1. The three chapters entitled Huihui lifa ("Islamic Calendar Method") in the Mingshi, the official history of the Ming Dynasty (1368-1644), which was completed in 1739. This text of the Huihui Ii seems to have been drastically shortened, lacks important parts such as the planetary mean motion tables and the star table, and contains comments relating the terminology of the Huihui li to that of Chinese calendars.

2. The Qizheng tuibu ("Motions of the Seven Planets"), a revision of the original Huihui li completed in 1477 by Bei Lin, vice-director of the Imperial Astronomical Observatory in Nanjing.

\footnotetext{
* Our research project on the Huihui li was financed by the Japan Society for the Promotion of Science.
} 
In 1781 the Qizheng tuibu was included in the Complete Books of the Four Imperial Archives, a collection of the most valuable books of that time made on the order of emperor Qian Long.

3. The "Outer Volume" of the Chiljong san ("Calculations of the Seven Planets", 1444), contained in the True Records of King Sejong in the official history of the Korean Yi Dynasty. This is a reworking of the Huihui li made on the order of the famous King Sejong (1419-1451). The original was recast in the form of a traditional Chinese calendar. Thus we find definitions of constants at the very beginning of the work, whereas tables and explanatory text were intermingled instead of included in separate volumes.

The three sources contain the following, partially irreconcilable, historical information concerning the origin of the Huihui li.

According to the Mingshi, the (probably Arabic or Persian) original was obtained in the capital of the defeated Yuan Dynasty by the first Ming emperor Hong Wu. In 1382 he ordered the Muslim Mashayihei and some others to translate the work into Chinese. In the beginning of the Qing Dynasty the book was lost and had to be reconstructed.

In the colophon of the Qizheng tuibu, Bei Lin writes that the Huihui li was brought to China in 1385 by a foreigner who became naturalized. Its Islamic computational methods were then translated into Chinese methods by the calendar official Yuan Tong. Because it was not frequently used in the following century, Bei Lin had to restore it.

Like various other Korean sources, the Chiljong san only states that the Huihui li was obtained by Korean scholars who visited China, but does not indicate a precise date.

In the records concerning Chinese families with the surname $\mathrm{Ma}$, Chen Jiujin found that Mashayihei came to China with his father and brothers in the year 1369. Furthermore, Chen noticed that several of the tables in the Huihui li were computed for a geographical latitude of $32^{\circ}$, very close to that of Nanjing. He thus concluded that when Mashayihei compiled the Huihui li he used new observations made at the observatory of the Ming capital Nanjing.

\section{New sources}

The Tōhoku manuscript In the library of Tōhoku University in Sendai (Japan) a manuscript was discovered which contains the Qizheng tuibu as well as the Mingyi Tianwen shu, a Chinese translation of an astrological handbook by the Persian astronomer Küshyār ibn Labbān (c. 1000). The latter is said to have been compiled by the same team of Ming astronomers that translated the Huihui li. The text of the Qizheng tuibu in the Tohoku manuscript is very close to that in the Complete Books of the Four Imperial Archives, but there are some remarkable differences. For instance, the title of the work is given as Huihui lifa; the name Qizheng tuibu appears nowhere in the Tohoku manuscript. Furthermore, the time of arrival in China of the foreigner who brought the original of the Huihui li is given as "the first years of the reign of Hong Wu" instead of the 18th year of Hong Wu (1385), which is more reconcilable with the historical information in the Mingshi and makes it possible that the foreigner concerned was Mashayihei or his father. The Töhoku manuscript has around twenty clear mistakes with respect to the Complete Books, but also seven improvements which are hard to imagine without access to a better text. A marginal note on the fourth sheet indicates that a number of sections was supplemented in the Office of the Complete Books of the Four Archives in 1774, seven years before the publication of the Qizheng tuibu. We conclude that the Tōhoku manuscript contains the version of Bei Lin's recension of the Huihui li which was used for inclusion in the Complete Books, the title Qizheng tuibu being added by the editors.

The fact that the Qizheng tuibu was actually entitled Huihui lifa made us suspect that it is much closer to the original Huihui li than we initially thought. A detailed comparison of the chapters Huihui lifa in the Mingshi and the Qizheng tuibu indeed showed that the former might very well have been based on the latter. In fact, the descriptions given in the Mingshi of all tables that were omitted or modified are in full agreement with the actual tables in the Qizheng tuibu. Furthermore, the explanatory texts in the Mingshi can often be derived from those in the Qizheng tuibu by leaving out or substituting repetitive parts of sentences.

The Sanjufiñ $\bar{\imath} \vec{\imath}$ The Bibliothèque Nationale in Paris possesses a unique manuscript of an Arabic, astronomical handbook written in Tibet in 1366 by a certain al-Sanjufini. Although his name indicates that al-Sanjufinī originated from the region around Samarkand in present-day Uzbekistan, 
he dedicated his $z \bar{j}$ to the Mongol viceroy of Tibet. The unique manuscript of the so-called Sanjufini $\mathrm{Z} \ddot{j}$, which was obtained in Beijing in the nineteenth century, contains marginal glosses in Mongolian and Tibetan and folio numbers in Chinese. An analysis of Herbert Franke showed that it was very probably written in Yongchang-fu, north-west of Lanzhou in the province Gansu.

A quick analysis of its mathematical tables shows that the Sanjufinī Zij is strongly related to the Huihui $l$. The two works have 18 tables in common, namely those for the lunar and planetary equations, lunar latitude, planetary stations, equation of time, oblique ascension, and parallax corrections. The Sanjufini $Z_{\bar{I} j}$ contains a set of tables giving the mean planetary positions and the true solar positions at respective vernal equinoxes. A preliı..inary analysis showed that these tables were very probably computed from the tables for planetary mean motion in the Huihui li. Whereas the text of the Huihui li prescribes a correction of the mean motions corresponding to a change in geographical longitude of $6 \frac{1}{2}$ degrees in eastward direction, the positions in the $Z_{\bar{j} j}$ of al-Sanjufini were corrected for a longitude difference of $14 \frac{1}{2}$ degrees in westward direction. This corresponds very well to the longitude difference between Beijing and al-Sanjufini's station Yongchang-fu. AlSanjufini writes that his tables are based on the "Jamāli observations", which may refer to Jamâl al-Dīn (or Zhamaluding), the first director of the Islamic Observatory in the early Yuan Dynasty.

Whereas the tables for planetary mean motion in the Sanjufīn $\bar{l} Z_{\bar{l} j}$ are dependent on those in the Huihui $l i$, the opposite seems to hold for the tables of planetary latitude. The Sanjufini $Z_{\bar{l} j}$ contains a variation of the standard type of latitude tables as found in Ptolemy's Almagest and most Islamic astronomical handbooks. The Huihui li includes a set of double-argument tables for planetary latitude, from which the latitudes can be read directly without any need of calculation. Since the tables in both sources share a set of planetary parameters which we have not found in any other zijes, we may assume that the double-argument tables in the Huihui li were computed from the tables found in the Zijj of al-Sanjufini. We thus conclude that the Huihui $l i$ and the Sanjufini $Z \bar{j} j$ both derive from an earlier source, possibly a work by the above-mentioned Jamāl al-Dīn or one of his colleagues at the Islamic Observatory in Beijing.

The Sanjufini $Z_{\overline{I j}}$ contains tables for two different geographical latitudes. Firstly, the value $38^{\circ} 10^{\prime}$ found in five tables can be considered to be al-Sanjufin's's "own" latitude, since it does not occur in the Huihui $l i$ at all and agrees very well with the latitude of Yongchang-fu. Secondly, the value $32^{\circ}$ occurs in at least two tables, both of which are also found in the Huihui li. The parallax table for latitude $32^{\circ}$ is indicated to be by al-Sanjufini, but this attribution is doubtful since the table is written in a different hand and inserted at a place where one would not expect it. Furthermore, unlike the Huihui li, al-Sanjufini does not use this parallax table to calculate solar eclipses. At any rate, because the tables in the Huihui li incorporating the latitude value $32^{\circ}$ also occur in a $z \bar{\imath} j$ which antedates the foundation of the Ming Dynasty (if only by two years), we must consider the possibility that they were not based on observations at the Ming observatory in Nanjing.

\section{Conclusion}

Our investigation of the three Chinese sources for the Huihui li already known, the manuscript of the Qizheng tuibu discovered at Tōhoku University, and the Arabic Sanjufiñ $\bar{Z} \bar{i} j$ has led to the following tentative conclusions:

The Huihui $l i$ is not directly related to any astronomical handbook written in the Muslim world, but was based on observations made in China. The most likely place and time of these observations was the Islamic Astronomical Observatory in Beijing in the beginning of the Yuan Dynasty. The majority of the tables now found in the Huihui li, in particular those for planetary motion, can be assumed to have been present in an Arabic or Persian work from the early Yuan Dynasty on which both the Huihui li and the $Z_{\overline{1} j}$ of al-Sanjufinin strongly depended. Original contributions to the Huihui li by Mashayihei and the other translators working under the first Ming emperor Hong Wu may include the set-up of the tables for planetary latitude as double-argument tables, the star catalogue, which Yabuuti dated to the early Ming, and possibly the tables for latitude $32^{\circ}$. A more detailed comparison of tables and explanatory text in the Huihui li and the Sanjufiñi $Z_{\bar{i} j}$ is likely to provide us with more information concerning the original form of the astronomical handbook(s) written by Muslim astronomers in the service of the Yuan Dynasty.

\section{Bibliography}

Benno van Dalen, E.S. Kennedy, and Mustafa K. Saiyid, "The Chinese-Uighur Calendar in Țūsī's Zijj-i Īlkhān $\vec{\imath}$, Zeitschrift für Geschichte der Arabisch-Islamischen Wissenschaften 11 (1997), pp. 111-152. 
Herbert Franke, "Mittelmongolische Glossen in einer arabischen astronomischen Handschrift von 1366", Oriens 31 (1988), pp. 95-118.

Willy Hartner, "The Astronomical Instruments of Cha-ma-lu-ting, their Identification, and their Relations to the Instruments of the Observatory of Marāgha", Isis 41 (1950), pp. 184-195.

Edward S. Kennedy, "Eclipse Predictions in Arabic Astronomical Tables Prepared for the Mongol Viceroy of Tibet", Zeitschrift für Geschichte der Arabisch-Islamischen Wissenschaften 4 (1987/88), pp. 60-80.

CHEN Jiujin, "Comparative Research Between the Huihui Calendar, Chiljōng Oepiǒn and Qizheng tuibu", in: Orjental Astronomy from Guo Shoujing to King Sejong, Proceedings of an International Conference (Seoul, Korea, 6-11 October 1993), Seoul 1997, pp. 105-111.

CHEN Meidong, "A Study of Some Astronomical Data in Muslim Calendar", in: History of Oriental Astronomy: Proceedings of an International Astronomical Union Colloquium No. 91 (New Delhi, India, 13-16 November 1985), Cambridge 1987, pp. 169-174.

Kiyosi Yabuuti, Chūgoku no tenmon-rekihō (Chinese Astronomy and Calendrical Sciences), Tokyo 1969.

Kiyosi Yabuuti, translated and partially revised by Benno van Dalen, "Islamic Astronomy in China during the Yuan and Ming Dynasties", Historia Scientiarum 7 (1997), pp. 11-43.

Michio Yano, Küšyār Ibn Labbān's 'Introduction to Astrology' (edition and translation), Tokyo 1997. 